\title{
Value of Helicobacter pylori Eradication on Platelet Count in chronic Hepatitis C Virus-Infected Patients with thrombocytopenia
}

Mohammed Elwan Mohammed, ${ }^{1}$ M.Sc., Mahmoud Mohammed Mousa Bazeed, ${ }^{1}$ PhD., Essam Abd-ElWahed Hassan., ${ }^{2}$ PhD., Mahmoud Abd Elrasheed Abd Elkhalek Allam, ${ }^{1}$ MD., Yusuf Abd-Allah Yusuf Nassar, ${ }^{1}$ MD., Ahmed Fathy Abd Elaziz Ibrahim, ${ }^{3}$ MD.

* Corresponding Author:

Mohammed Elwan Mohammed Mohamedelwan88@yahoo.com Received for publication April 16, 2021; Accepted June 20, 2021; Published online June 20, 2021, 2021.

Copyright The Authors
published by Al-Azhar
University, Faculty of Medicine,
Cairo, Egypt. Users have the
right to read, download, copy,
distribute, print, search, or link
to the full texts of articles under
the following conditions:
Creative Commons Attribution-
Share Alike 4.0 International
Public License (CC BY-SA 4.0).
doi: 10.21608/aimj.2021.70828.1454.
I. Internal Medicine Department,
Faculty of Medicine, Al-Azhar
University, Cairo, Egypt.
2. Internal Medicine Department,
Faculty of Medicine, Ain Shams
University Cairo, Egypt.
3. Clinical Pathology Department,
Faculty of Medicine, Al-Azhar
University, Cairo, Egypt.

\begin{abstract}
Background: Invasive therapies are often needed for sufferers with chronic liver diseases (CLDs). Thrombocytopenia is common hematological abnormality in CLD sufferers. In immune thrombocytopenic purpura (ITP), Helicobacter pylori (HP) infection is linked to a low platelet count, whereas HP eradication is associated to an increase in platelet count. In Egypt, the most common trigger of CLD is infection with the hepatitis $\mathrm{C}$ virus. In Egypt HP is common infection happens at a young age.

Aim of the study: The impact of Helicobacter pylori eradication on platelet count in HCV-related CLD patients with thrombocytopenia.

Patients and Methods: A prospective study of 100 patients divided to HP positive and HP negative.

Sufferers that checked positive for HP have been given treatment to eliminate the virus. HP eradication was evaluated using a stool test for Helicobacter pylori antigen 6 weeks following the treatment was completed. Platelet counts were used to assess the success of HP eradication after 1, 3, 6, and 9 months of follow-up.

Results: HP infection prevalence among HCV patients $65 \%(65 / 100)$ versus 35\% (35/100) HP negative. Eradication in HP positive patients after treatment were 46 patients $(70.8 \%)$ and 19 patients $(29.2 \%)$ not eradicate. platelets response after HP therapy there were 14 patients $(21.5 \%)$ with complete response, 20 patients $(30.8 \%)$ had a partial response, while 31 had no response $(47.7 \%)(12$ eradicated and 19 not eradicated).

Conclusion: Successfully eradicating H. pylori can have an impact on platelet recovery and platelet count maintenance in patients with chronic $\mathrm{HCV}$-infected thrombocytopenia.
\end{abstract}

Keywords: Hepatitis C Virus-; Helicobacter pylori; thrombocytopenia

Disclosure: The authors have no financial interest to declare in relation to the content of this article. The Article Processing Charge was paid for by the authors.

Authorship: All authors have a substantial contribution to the article.

\section{INTRODUCTION}

Endoscopic therapies for gastro-esophageal varices, radiofrequency ablation for hepatocellular carcinoma (HCC), and interventional radiology for portal hypertension are some of the invasive treatments required of sufferers with chronic liver disease (CLD). Thrombocytopenia, defined as a platelet count of $<100000 / \mu \mathrm{L}$, has been the most frequent hematological anomaly in sufferers with chronic liver diseases (CLDs). It's a major problem that comes with a high risk of bleeding. ${ }^{1}$

Thrombocytopenia affects $64-76 \%$ of CLD patients with cirrhosis and/or fibrosis, relative to just $6 \%$ of non-cirrhotic CLD patients. Two of the most popular reasons of thrombocytopenia are splenomegaly and hypersplenism. Nevertheless, thrombocytopenia in CLD patients is not necessarily associated with splenomegaly, and other factors may be at play in the patient's lower platelet count. ${ }^{2}$

In sufferers with immune thrombocytopenic purpura (ITP), Helicobacter pylori (H. pylori) infection is related to a lower platelet count. Although eradication of $\mathrm{H}$. pylori is a proven treatment for raising platelet counts in ITP patients, it is unknown if eradication can similarly impact platelet counts in CLD patients. ${ }^{1}$

In Egypt, infection with (HCV) is the most frequent reason of CLD. Thrombocytopenia develops in HCV 
patients due to a variety of causes, which could be categorized into those that cause reduced output, splenic sequester, and raised destruction. ${ }^{3}$

Hepatitis $\mathrm{C}$ virus (HCV) causes a wide range of hepatic complications, from chronic inflammation to cirrhosis and hepatocellular carcinoma. ${ }^{4}$

Because of the high mortality and morbidity associated with liver disease, the incidence of HCV infection differs across the world. Egypt has a higher incidence of hepatitis $\mathrm{C}$ infection. $\mathrm{HCV}$ antibodies are present in nearly $6.3 \%$ of blood donors. ${ }^{5}$

The path of HCV-related liver illness differs significantly with one patient to the next. Numerous variables have been linked to fibrosis development, which include age at exposure, male gender, length of infection, alcohol consumption, viral immune response, and steatosis. Nevertheless, disease development can be observed in certain patients even when such factors are absent, implying that other factors are involved. Environmental factors, like bacterial co-infection, or host genetic factors can all play a role.

In Egypt, HP infection is normal, and infection can happen at a very early age.

HP antibodies were present in $55.6 \%$ of $\mathrm{HCV}$ infected patients, compared to $39.4 \%$ of healthy controls, according to an Egyptian study. Moreover, cirrhotic patients had a higher incidence of HP infection than non-cirrhotic patients. ${ }^{7}$

The link among HP infection and the intensity of chronic hepatic disease in HCV sufferers has been reported in various parts of the worldwide. ${ }^{8}$

The role of $\mathrm{H}$. pylori eradication on platelet counts in sufferers with HCV-related chronic liver disease and thrombocytopenia is assessed.

\section{PATIENTS AND METHODS}

The current prospective study involved 100 patients with HCV-related thrombocytopenia, Attending Hematology unit, internal medicine Department, Faculty of Medicine, Al Hussein Hospital, Al-Azhar University

All patients will subject to:

Detailed history talking including drug history that may be implicated in thrombocytopenia, weight loss, arthritis, skin changes, bleeding tendency and lymph node swelling.

Physical examination for demonstration of important signs as liver condition, bleeding disorders, pallor, lymphadenopathy and /or splenomegaly.

Laboratory investigations: Platelet count, the prothrombin time (PT), and liver function tests (total $\&$ direct bilirubin, AST, ALT, albumin, and alkaline phosphatase) Peripheral blood smear examination for pseudo-thrombocytopenia. Reticulocytic count\& Bone marrow aspiration for patients with low Reticulocytic count, Anti-platelets Antibody.

Abdominal Ultrasonography for presence of splenomegaly and evidence of cirrhosis.

$\mathrm{HCV}$ infection was verified by $\mathrm{HCV}$ antibody positivity HCV RNA quantification by PCR (polymerase chain reaction)

In HCV-infected patients, the level of $\mathrm{H}$. pyloriantigen in the stool was used to determine the presence of $\mathrm{H}$. pylori infection.

Patients that test positive for $\mathrm{H}$. pylori will then receive standard triple therapy (Standard H. pylori Eradication Therapy. For duration of, two weeks Amoxicillin $1 \mathrm{~g}$ twice daily, Clarithromycin 500mg twice daily, and Omeprazole 20mg twice daily will be given. H. pylori-antigen in stool will be used to confirm eradication 6 weeks after stopping omeprazole or the other acid suppressant.

Patients that failed to eradicate $\mathrm{H}$. pylori with firstline treatment would be treated with an alternative second-line treatment (levofloxacin-based therapy). For duration of, 14 days amoxicillin 1 gram twice daily, levofloxacin 500mg once daily, and omeprazole $20 \mathrm{mg}$ twice daily will be given.

At 1, 3, 6, and 9 months following the final eradication treatment, platelet (PLTS) counts will be used to determine the response.

The disease response will be divided into three groups:

Complete response (CR): platelet count $\geq 100000$ $/ \mu \mathrm{L}$,

Partial response (PR): platelet count 50-100 000/ $\mathrm{LL}$ or doubling of pre- treatment platelet count

No response (NR): platelet count $<50000 / \mu \mathrm{L}$ or an increase of $<20000 / \mu \mathrm{L}$ or no doubling of pretreatment platelet count after at least 9 months of follow-up.

Ethical considerations: all procedures will follow AlAzhar University Ethical committee regulations and patient consent will be taken from all patients

Statistical analysis: The data was analyzed using the Statistical Program for Social Science (SPSS). The mean \pm standard deviation (SD) will be used to express the numerical variables. Platelet counts before and after treatment was compared. A P-value of less than 0.05 has been deemed statistically significant, while a P-value of greater than 0.05 has been deemed non- significant. The P-value must be less than 0.001 to be highly statistically significant 


\section{RESULTS}

The current prospective research involved 100 patients with HCV -related thrombocytopenia, Attending the Hematology Unit of the Department of Internal Medicine at the Faculty of Medicine, Al Hussein Hospital, Al-Azhar University. There was male predominance (69) male, (31) female and mean age $(51.5 \pm 5)$. The patients have been divided into two categories:

There were 65 patients with $\mathrm{HCV}$ and active $\mathrm{H}$. Pylori.

There were 35 patients with $\mathrm{HCV}$ but no active $\mathrm{H}$. Pylori.

No statistical significant difference (p-value> 0.05) was found between studied groups as regard sex, Highly statistical significant difference ( $\mathrm{p}-$ value < 0.001 ) among studied groups as regard age (Table 1). No statistical significant difference (p-value> 0.05) was found among the studied groups as regard liver \& kidney functions (ALT, AST, PT, ALB, total bilirubin, direct bilirubin \& Creat) (Table 2).

In terms of $\mathrm{Hb}$ and WBCs, there was no statistically significant difference ( $p$-value $>0.05$ ) among the studied groups. In terms of PLTs, there is a highly statistically significant difference ( $\mathrm{p}$-value $<0.001$ ) among the studied groups (Table 3 ).

There was no statistically significant difference in liver status among the studied groups (p-value > $0.05)$. In terms of spleen size, there was a statistically significant difference (p-value $<0.05)$ among the studied groups (Table 4). the description of Eradication and response of platelets to treatment in $\mathrm{H}$ pylori positive patients was shown in (Table 5). As regard Eradication, there were 46 patients $(70.8 \%)$ eradicated and 19 patients (29.2\%) not eradicated examined by negative $h$ pylori $\mathrm{Ag}$ in stool after receive $\mathrm{h}$ pylori treatment eradication. As regard PLTs response, there were 14 patients $(21.5 \%)$ with complete response, there were 20 partial responses $(30.8 \%)$ and 31 no responses (47.7\%) (12 eradicated and 19 not eradicated).

There was no statistical significant difference (pvalue> 0.05) of AST, ALB, bilirubin, Creat, WBCs \& PLTs as regard Eradication, Statistically significant difference (p-value $<0.05$ ) of PT as regard Eradication, Highly statistical significant difference ( $\mathrm{p}$ - value < 0.001) of $\mathrm{Hb}$ as regard Eradication (Table 6). Also, we did not find statistical significant difference ( $p$-value $>0.05$ ) of liver status \& spleen size as regard Eradication (Table 7).

There was no statistical significant difference (pvalue> 0.05) of PT, ALB, total bilirubin, direct bilirubin, Creat \& WBCs as regard response, Statistically significant difference $(p-v a l u e<0.05)$ of $\mathrm{Hb}$ as regard response, Highly statistical significant difference ( $\mathrm{p}$ - value $<0.001)$ of PLTs as regard response (Figure 1, Table 8 ).

We found statistically significant difference (p-value $<0.05)$ of liver status \& spleen size as regard response (Figure 2, Table 9).

\begin{tabular}{|c|c|c|c|c|c|c|}
\hline & & \multicolumn{4}{|c|}{$\mathrm{H}$ pylori $\mathrm{Ag}$} & \multirow[t]{2}{*}{ P-value } \\
\hline & & \multicolumn{2}{|c|}{ Negative $(\mathrm{N}=35)$} & \multicolumn{2}{|c|}{ Positive $(\mathrm{N}=65)$} & \\
\hline \multirow{2}{*}{$\begin{array}{l}\text { Age } \\
\text { (years) }\end{array}$} & Mean & \multicolumn{2}{|c|}{48.2} & \multicolumn{2}{|c|}{54.8} & \multirow[t]{2}{*}{$<0.001 \mathrm{HS}$} \\
\hline & $\pm \mathrm{SD}$ & \multicolumn{2}{|c|}{4.8} & \multicolumn{2}{|c|}{5.2} & \\
\hline \multirow[t]{2}{*}{ Sex } & Male & 25 & $71 . \%$ & 44 & $67.7 \%$ & \multirow[t]{2}{*}{$0.7 \mathrm{NS}$} \\
\hline & Female & 10 & $28 . \%$ & 21 & $32.3 \%$ & \\
\hline
\end{tabular}

Table 1: Comparison between studied groups as regard age \& sex. (NS: p-value $>0.05$ is regarded as nonsignificant, HS: p-value $<0.001$ is regarded as highly significant).

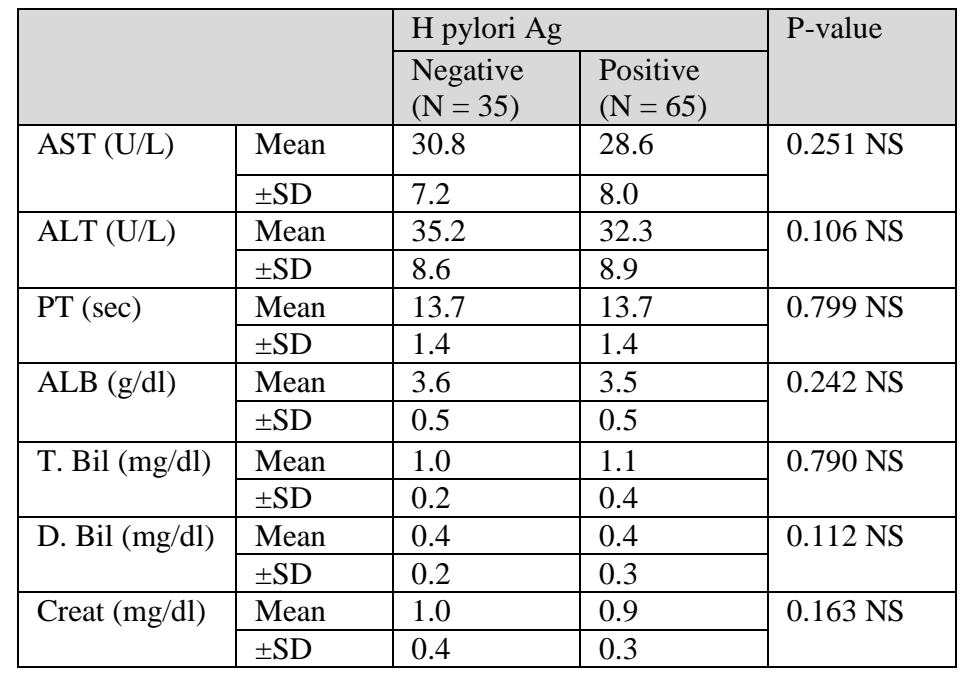

Table 2: Comparison between studied groups as regard liver \& kidney functions. (NS: p-value > 0.05 is regarded as non-significant). 


\begin{tabular}{|c|c|c|c|c|}
\hline & \multicolumn{2}{|c|}{$\mathrm{H}$ pylori $\mathrm{Ag}$} & \multirow[t]{2}{*}{ P-value } \\
\hline & & $\begin{array}{l}\text { Negative } \\
(\mathrm{N}=35)\end{array}$ & $\begin{array}{l}\text { Positive } \\
(\mathrm{N}=65)\end{array}$ & \\
\hline \multirow[t]{2}{*}{$\mathrm{Hb}(\mathrm{g} / \mathrm{dl})$} & Mean & 11.8 & 11.3 & \multirow[t]{2}{*}{$0.1 \mathrm{NS}$} \\
\hline & $\pm \mathrm{SD}$ & 1.5 & 1.3 & \\
\hline \multirow[t]{2}{*}{ WBCs (x103/ul) } & Mean & 5.8 & 5.7 & \multirow[t]{2}{*}{$0.782 \mathrm{NS}$} \\
\hline & $\pm \mathrm{SD}$ & 1.8 & 1.8 & \\
\hline \multirow[t]{2}{*}{ PLTs (x103/ul) } & Mean & 66.1 & 42.2 & \multirow[t]{2}{*}{$<0.001 \mathrm{HS}$} \\
\hline & $\pm \mathrm{SD}$ & 18.8 & 20.8 & \\
\hline
\end{tabular}

Table 3: Comparison among studied groups as regard baseline CBC. (NS: p-value $>0.05$ is regarded as nonsignificant, HS: p-value $<0.001$ is regarded as highly significant).

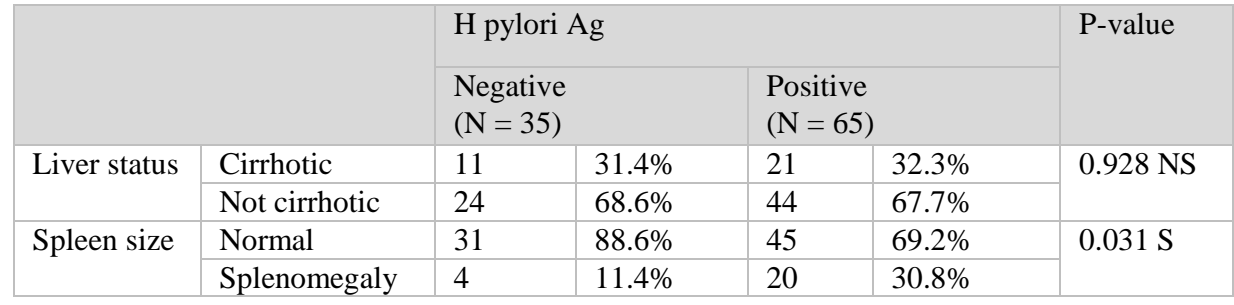

Table 4: A comparison of the studied groups in terms of U/S. (NS: p-value $>0.05$ is regarded as non-significant, $\mathrm{S}: \mathrm{p}$-value $<0.05$ is regarded as significant).

\begin{tabular}{|l|l|l|l|}
\hline \multicolumn{2}{|c|}{} & \multicolumn{2}{c|}{ H pylori positive patients } \\
Eradication & Eradicated & 46 & $70.8 \%$ \\
\cline { 2 - 4 } & Not eradicated & 19 & $29.2 \%$ \\
\hline \multirow{3}{*}{ Response of PLTs to therapy } & Complete response & 14 & $21.5 \%$ \\
\cline { 2 - 4 } & Partial response & 20 & $30.8 \%$ \\
\cline { 2 - 4 } & No response & 31 & $47.7 \%$ \\
\hline
\end{tabular}

Table 5: Description of Eradication and response of PLTs in H pylori positive patients.

\begin{tabular}{|c|c|c|c|c|c|c|}
\hline & \multicolumn{4}{|c|}{ Eradication } & \multirow{3}{*}{$\begin{array}{l}\text { P-value } \\
0.862 \text { NS }\end{array}$} \\
\hline & & \multicolumn{2}{|c|}{ Yes $(n=46)$} & \multicolumn{2}{|c|}{ No $(\mathrm{n}=19)$} & \\
\hline AST & Mean \pm SD & 28.5 & \pm 8.8 & 28.8 & \pm 6.1 & \\
\hline ALT & Mean \pm SD & 35.9 & \pm 7.5 & 23.6 & \pm 5.4 & $<0.001 \mathrm{HS}$ \\
\hline PT & Mean \pm SD & 14.0 & \pm 1.4 & 13.0 & \pm 0.9 & $0.009 \mathrm{~S}$ \\
\hline ALB & Mean \pm SD & 3.4 & \pm 0.6 & 3.5 & \pm 0.4 & $0.610 \mathrm{NS}$ \\
\hline T Bil & Mean \pm SD & 1.1 & \pm 0.5 & 1.0 & \pm 0.3 & $0.219 \mathrm{NS}$ \\
\hline D Bil & Mean \pm SD & 0.4 & \pm 0.4 & 0.4 & \pm 0.3 & $0.933 \mathrm{NS}$ \\
\hline Creat & Mean \pm SD & 0.9 & \pm 0.3 & 0.9 & \pm 0.3 & $0.857 \mathrm{NS}$ \\
\hline $\mathrm{Hb}$ & Mean \pm SD & 11.7 & \pm 1.3 & 10.4 & \pm 0.8 & $<0.001 \mathrm{HS}$ \\
\hline WBCs & Mean \pm SD & 5.8 & \pm 1.8 & 5.4 & \pm 1.8 & $0.469 \mathrm{NS}$ \\
\hline PLTs & Mean \pm SD & 41.2 & \pm 20.9 & 44.6 & \pm 20.7 & $0.551 \mathrm{NS}$ \\
\hline
\end{tabular}

Table 6: Comparisons of laboratory data as regard eradication (S: p-value $<0.05$ is regarded as significant., HS: pvalue $<0.001$ is regarded as highly significant, NS: p-value $>0.05$ is regarded as non-significant).

\begin{tabular}{|c|c|c|c|c|c|c|c|}
\hline & \multicolumn{4}{|c|}{ Eradication } & \multirow[t]{2}{*}{$\mathrm{X} 2$} & \multirow[t]{2}{*}{ P-value } \\
\hline & & \multicolumn{2}{|c|}{ Yes $(n=46)$} & \multicolumn{2}{|c|}{ No $(n=19)$} & & \\
\hline \multirow[t]{2}{*}{ Liver status } & Cirrhotic & 14 & $30.4 \%$ & 7 & $36.8 \%$ & \multirow[t]{2}{*}{0.25} & \multirow[t]{2}{*}{$0.615 \mathrm{NS}$} \\
\hline & Not cirrhotic & 32 & $69.6 \%$ & 12 & $63.2 \%$ & & \\
\hline \multirow[t]{2}{*}{ Spleen size } & Normal & 30 & $65.2 \%$ & 15 & $78.9 \%$ & \multirow[t]{2}{*}{1.19} & \multirow[t]{2}{*}{$0.275 \mathrm{NS}$} \\
\hline & Splenomegaly & 16 & $34.8 \%$ & 4 & $21.1 \%$ & & \\
\hline
\end{tabular}

Table 7: comparisons U/S as regard Eradication (NS: p-value > 0.05 is regarded as non-significant). 


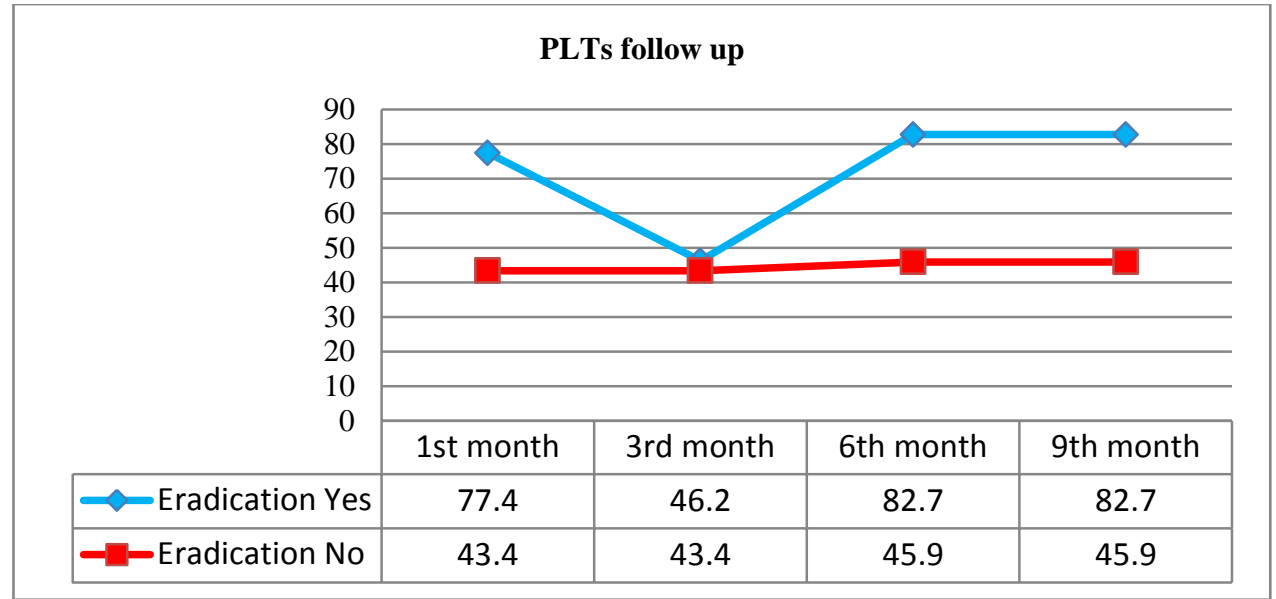

Fig 1: Comparisons PLTs follow up as regard Eradication.

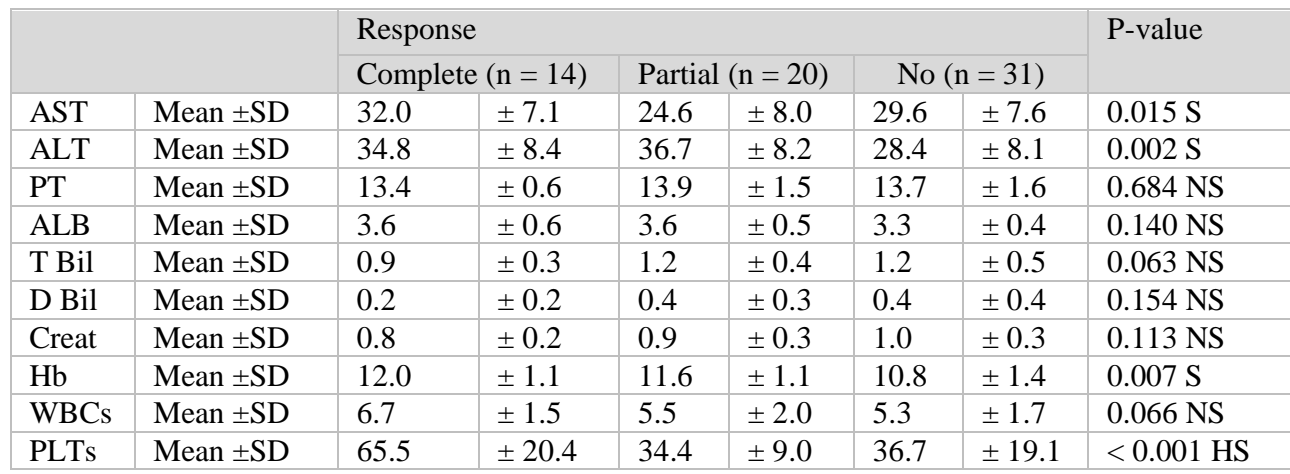

Table 8: Comparisons of laboratory data as regard response of PLTs (S: p-value $<0.05$ is regarded as significant, HS: $p$-value $<0.001$ is regarded as highly significant ., NS: p-value $>0.05$ is regarded as non-significant).

\begin{tabular}{|c|c|c|c|c|c|c|c|c|}
\hline & \multicolumn{6}{|c|}{ Response } & \multirow[t]{2}{*}{ P-value } \\
\hline & & \multicolumn{2}{|c|}{ Complete $(\mathrm{n}=14)$} & \multicolumn{2}{|c|}{ Partial $(n=20)$} & \multicolumn{2}{|c|}{ No $(n=31)$} & \\
\hline \multirow[t]{2}{*}{ Liver status } & Cirrhotic & 0 & $0 \%$ & 8 & $40 \%$ & 13 & $41.9 \%$ & \multirow[t]{2}{*}{$0.014 \mathrm{~S}$} \\
\hline & Not cirrhotic & 14 & $100 \%$ & 12 & $60 \%$ & 18 & $58.1 \%$ & \\
\hline \multirow[t]{2}{*}{ Spleen size } & Normal & 14 & $100 \%$ & 16 & $80 \%$ & 15 & $48.4 \%$ & \multirow[t]{2}{*}{$0.001 \mathrm{~S}$} \\
\hline & Splenomegaly & 0 & $0 \%$ & 4 & $20 \%$ & 16 & $51.6 \%$ & \\
\hline
\end{tabular}

Table 9: Comparisons U/S as regard response of PLTs ( $\mathrm{S}$ : $\mathrm{p}$-value $<0.05$ is regarded as significant).

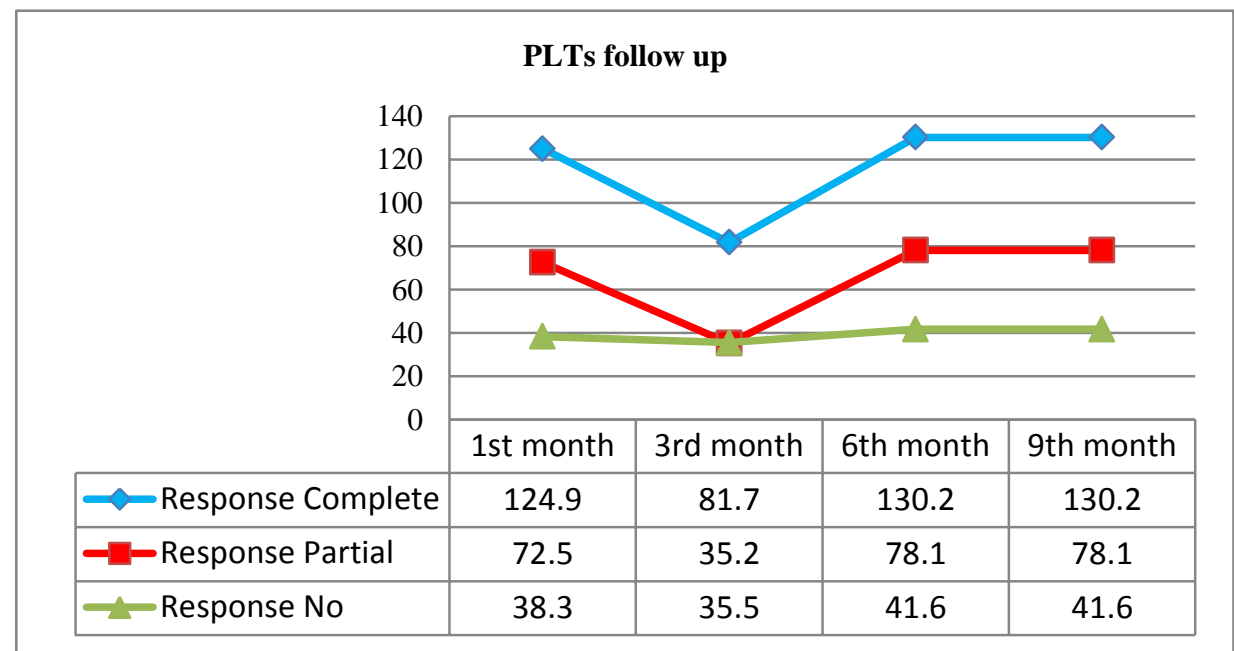

Fig 2: Comparisons PLTs follows up after therapy as regard response of PLTs.. 


\section{DISCUSSION}

Invasive treatment is often required for patients with (CLD). Thrombocytopenia happens in $64-76 \%$ of CLD patients with cirrhosis and/or fibrosis, relative to $6 \%$ of non-cirrhotic CLD patients. Thrombocytopenia is commonly caused by splenomegaly and hypersplenism. Nevertheless, thrombocytopenia in CLD patients is not necessarily associated with splenomegaly, and other factors can be at play in the patient's lower platelet count. ${ }^{2}$

The most popular reason of CLD in Egypt is hepatitis $\mathrm{C}$ virus (HCV) infection; few researchers studied the impact of HP on Platelet Count in thrombocytopenia patients with Chronic HCV Infection.

In our study, H. pylori infection recorded prevalence among HCV patients with thrombocytopenia $65 \%$ $65 / 100)$ versus $35 \%(35 / 100) \mathrm{H}$. pylori negative this agreement with Takashima et al (2016) ${ }^{1}$ The research included sixty-five patients with $\mathrm{HCV}$ related CLD and thrombocytopenia, of which 30 $(46 \%)$ were H. pylori- positive. in contrast to Ibrahim et al., (2018) ${ }^{9}$ Using ELISA and IHC, respectively, the average incidence of $\mathrm{H}$. pylori was $10.81 \%$ and $8.00 \%$. Aljarad S et al., (2018) ${ }^{10}$ and Lee et al., (2020) ${ }^{11}$ reported the frequency of Helicobacter pylori infection was $72 \%$ and $54.3 \%$ respectively in ITP patients in contrast to Sultan et al., (2016) ${ }^{12}$ show frequency of Helicobacter pylori infection in ITP $11.1 \%$. The approaches used to detect $\mathrm{H}$. pylori varied between the studies, which may explain why the positivity rates were so different. Some of the research used serology to identify and diagnose $\mathrm{H}$. pylori infection, while others used PCR-based approaches.

During the research period, Eradication in $\mathrm{H}$ pylori positive patients after treatment were 46 patients (70.8\%) eradicated and 19 patients (29.2\%) not eradicate This was consistent with Hanafy et al., (2016) ${ }^{13}$ One month after terminating treatment, 169 $(68.1 \%)$ patients had helicobacter eradication, as shown by the absence of $\mathrm{H}$. Pylori fecal antigen, In chronic ITP, Furusyo et al., (2011) ${ }^{14}$ reported a 91.0 $\%$ (61 of 67) rate of effective eradication. Lee et al., (2020) ${ }^{11}$ calculated the total eradication with first and second therapy became $93.9 \%$ (46/49).

We observe the effect of eradicating $\mathrm{H}$. pylori on platelet counts during the study period in HCVrelated CLD patients with thrombocytopenia. Our results indicate an increase in PLT response following $\mathrm{H}$ pylori eradication, there were 14 patients (21.5\%) with complete response, 20 patients (30.8\%) with partial response (over all response 34 patients $(52.3 \%) \& 31$ patients $(47.7 \%)$ with no response $\{12$ eradicated and 19 not eradicated $\}$. This was consistent with Hanafy et al (2016) ${ }^{13}$ who report platelet counts one month after eradication show a statistically significant difference from pretreatment $(p=0.000)$. The platelet count of non-responders improved just slightly or not at all $(\mathrm{p}=0.4)$. As previously mentioned by Pogorzelska et al. (2017) ${ }^{15}$, eradication of this bacteria resulted in an increase in platelet number, allowing antiviral treatment to be administered (with interferon) Furthermore, antiviral treatments were more effective in people that had previously been treated for $\mathrm{H}$. pylori. Similar results were reported by others in chronic ITP. ${ }^{11}$

In contrast, other studies found that eradication treatment has no favorable impact on platelet recovery. Just $6.7 \%$ of treated patients had elevated platelet counts; according to Ahn et al. (2006) ${ }^{16}$ from the United States. Similar results were reported ${ }^{17,18}$. Lastly, a Malaysian report discovered that eradicating the infection had no long-term impact on platelet recovery ${ }^{19}$. The response of platelets to eradication treatment varies dramatically between nations.

Our study shows all patients with complete platelets response have not splenomegaly, not cirrhotic and with splenomegaly and cirrhosis response rate decrease.

Despite this obvious connection, there has been some variation in platelet count responses to $H$. pylori eradication therapy across studies, These contraindicating studies on the impact of $\mathrm{H}$. pylori eradication on platelet response could be attributable to the occurrence of various $H$. pylori strain characteristics across areas, with a greater prevalence in developing countries than developed countries, as well as genetic and bacterial factors, These findings together may influence the outcomes and indicate that the factors that collaborately control the host's inflammatory response to the bacterium may account, at least partly, for the variable response to H. pylori eradication treatment which warrants further prospective studies with a larger sample size, as well as research into the mechanism behind $\mathrm{H}$. pylori and HCV pathogenicity, will be needed to confirm our results regarding platelet response among study groups and the optimal overall increase in platelet count after 6 months of eradication.

\section{CONCLUSION}

The successful eradication of H. Pylori can influence platelet recovery and platelet count maintenance in patients with chronic HCV-infected thrombocytepenia. Finally, the findings of this research support the eradication of $\mathrm{H}$. pylori infection in patients suffering from HCV-related thrombocytopenia. Since this is easy, cost-effective, short term, secure, noninvasive with favorable results, no drugs toxicity and prevents pharmaceutical agents with several adverse effects including steroids, prevents costly therapy like thrombopoietin agonists and prevents invasive maneuvers like splenectomy and partial splenic embolization that are risky for advanced liver disease sufferers. 


\section{REFERENCES}

1. Takashima T, Enomoto H, Iwata Y, et al. Effects of Helicobacter pylori Eradication on the Platelet Count in Hepatitis C Virus Infected Patients. $J$ Clin Med Res. 2016;8(12):854-8

2. Mitchell O, Feldman DM, Diakow M, et al. The pathophysiology of thrombocytopenia in chronic liver disease. Hepat Med. 2016 15;8:39-50.

3. Madkour N, Ghanem A, El-melegy S, et al. Effect of Helicobacter pylori on Treatment of Hepatitis C Virus Egyptian Patients. Donnish Journal of Biomedical Research. 2016; 3(2):13-8.

4. Butel JS. Virology. In: Brooks GF, Carroll KC, Butel JS, editors. Medical microbiology. New York: Mc Graw Hill. 2007; 567-620

5. El-Zanaty and Associates [Egypt], Ministry of Health and Population [Egypt] and ICF International. Egypt Health Issues Survey 2015. Cairo, Egypt and Rockville, Maryland, USA: Ministry of Health and Population and ICF International

6. Caste'ra L, Pedeboscq A, Rocha M, et al. Relationship between the severity of hepatitis $\mathrm{C}$ virus-related liver disease and the presence of Helicobacter species in the liver: a prospective study. World J Gastroenterology. 2006; 12(45):7278-84

7. El-Masry S, El-Shahat M, Badra G, et al. Helicobacter pylori and Hepatitis C Virus Coinfection in Egyptian Patients. Journal of Global Infectious Diseases. 2010; 2(1):4-9

8. Wang J, Chen RC, Zheng YX, et al. Helicobacter pylori infection may increase the risk of progression of chronic hepatitis B disease among the Chinese population: a meta-analysis. Int $J$ Infect Dis. 2016; 50:30-7.

9. Ibrahim H., El Shaer R., El Elaimy IA, et al. Serological and Immunohistochemical Detection of Helicopacter pylori Infection among Egyptian Hepatitis C Virus Patients. Afro- Egyptian Journal of Infectious and Endemic Diseases. 2018; 8(3): 121-8

10. Aljarad S., Alhamid A., Tarabishi AS, et al. The impact of helicobacter pylori eradication on platelet counts of adult patients with idiopathic thrombocytopenic purpura. BMC Hematol. 2018; $18(1): 2-8$

11. Lee A., Hong J., Chung H., et al. Helicobacter pylori eradication affects platelet count recovery in immune thrombocytopenia. Scientific reports 2020; 10(1):9370.

12. Sultan S, Irfan SM, Kaker J, et al. Efficacy of helicobacter pylori eradication as an upfront treatment of secondary immune thrombocytopenia: an experience from Pakistan. The Medical journal of Malaysia. 2016; 71(2) :53-6

13. Hanafy AS, El Hawary AT, Hamed EF, et al. Impact of Helicobacter pylori eradication on refractory thrombocytopenia in patients with chronic HCV awaiting antiviral therapy. Eur $J$ Clin Microbiol Infect Dis. 2016; 35(7):1171-6.

14. Furusyo N, Walaa AH, Eiraku K, et al. Treatment for Eradication of Helicobacter pylori Infection among Chronic Hepatitis C Patients. Gut and liver. 2011; 5(4):447-53.
15. Pogorzelska J., Łapińska M., Kalinowska A, et al. Helicobacter pylori infection among patients with liver cirrhosis. European journal of gastroenterology \& hepatology. 2017; 29(10): 1161-5.

16. Ahn ER, Tiede MP, Jy W, et al. Platelet activation in Helicobacter pylori-associated idiopathic thrombocytopenic purpura eradication reduces platelet activation but seldom improves platelet counts. Acta Haematol. 2006; 116(1): 1924

17. Stasi R, Rossi Z, Stipa E, et al. Helicobacter pylori eradication in the management of patients with idiopathic thrombocytopenic purpura. Am J Med. 2005; 118(4): 414-9.

18. Michel M., Cooper N., Jean C., et al. Does Helicobater pylori initiate or perpetuate immune thrombocytopenic purpura?. Blood. 2004; 103(3): 890-6.

19. Gan GG, Norfaizal AL, Bee PC, et al. Helicobacter pylori infection in chronic immune thrombocytopenic purpura patients in Malaysia. Med J Malaysia. 2013; 68(3): 231-3 